\title{
In Nanaku: Local Knowledge of The Coastal Fishermen Community Taniwel Seram
}

\author{
Sem Touwe ${ }^{1 *} ;$ Alamsyah $^{2}$ \\ ${ }^{1}$ Lecture of Study Programe of History Education, Faculty of Teacher Training and Education \\ Pattimura University, Maluku - Indonesia \\ ${ }^{2}$ Lecture of Department History, Faculty of Humanities, Diponegoro University, Semarang - \\ Indonesia
}

\begin{abstract}
This paper wants to explain how Nanaku, as local knowledge of the coastal community in Taniwel sub-district, western Seram Regency had an important role in the marine activities. The purpose of the study was to explain the local knowledge of the community related to the skills and accuracy in marking natural phenomena related to marine activities. This study used descriptive qualitative methods, which included data collection, data reduction, data presentation, and drawing conclusions or verification. The results showed that Nanaku was passed down from generation to generation. Through this local knowledge, they can hold the process of making boats and fishing in the sea properly. This local knowledge was used as a natural marker and fishing guideline. Nanaku consisting of twelve fishing skills; nanaku moon, nanaku karti star, nanaku beluku star, nanaku scaly clouds, nanaku high and low tide, nanaku whirl wind, nanaku ocean currents, nanaku when river water overflows/ floods , nanaku seagulls lock, nanaku owl (boel), nanaku lunar eclipse, and nanaku lightning in Northeast at night. The conclusion showed that Nanaku still survives today and was not lost in the midst of technological developments. Nanaku became a basic knowledge for a fishing profession which contributed to the economic life of the coastal fishing communities of Taniwel Seram.
\end{abstract}

\section{Introduction}

Local knowledge system or indigenous knowledge is a natural phenomenon that is seen, felt, experienced or thought, formulated according to the pattern and way of thinking of a community. Indigenous knowledge in its development is constructed differently, and its meaning tends to reflect the existence of various relationships or powers over the 'amalgamation' of the parties that construct it [1]. For the people who support local wisdom, what they have is a reflection of their cultural and religious meaning, which is then passed down from generation to generation [2].

Traditional wisdom related to the natural marine environment includes a number of knowledges resulting from cultural products related to the patterns of utilization and management of marine natural resources where they live [3]. As living beings, humans are best able to adapt to their environment and always try to take advantage of the existing

\footnotetext{
*Corresponding Author: drs.semt@yahoo.com
} 
resources to support their daily needs. This causes a bond between humans and their natural environment. The bond gives experiences and knowledge as well as thoughts to humans, how they treat the natural environment they have. The local knowledge system is one of the cultural elements that are universal; however simple it is, culture is considered as a unitary complex in which there are knowledge, beliefs, arts, morals, laws, customs and other things that are acquired by humans as members of a community [4].

Fishing communities with simple fishing technology systems often rely on the ability to mark natural signs in catching fish [5], as done by the coastal community of Taniwel subdistrict. They depend on their livelihoods as fishermen on their local knowledge system. These fishermen use simple technology such as fishing rods, nets, trawls, boats, torches, petromax lamps, and others. The catch depends on the traditional knowledge skill called "Nanaku". Nanaku is knowledge related to the natural signs when they are going to fish in the sea.

As a natural marker, Nanaku for Maluku people is understood as the basis of supernatural beliefs or beliefs that are considered sacred [6]. This knowledge is a form of knowledge from the adaptation of the Taniwel coastal fishing community to the natural environment. This knowledge is a tradition inherited from generation to generation. This knowledge inheritance occurs vertically to their descendant, and horizontally, that is, from one human to another, from the older generation to the younger generation [7].

Therefore "nanaku" is seen as a form of local wisdom regarding traditional knowledge related to fishing activities that support increased catches. On that basis, this article will critically explain nanaku as a traditional knowledge that is very useful for fishermen on Taniwel sub-district coast which includes Lisabata, Taniwel, Hulung, and Kasieh villages, West Seram Regency. Through this article, an inventory of local knowledge systems and a complete understanding of nanaku will be obtained.

\section{Method}

The explanation of this article uses descriptive qualitative research methods. Through this method, various cultural phenomena will be described in the form of natural signs and aspects related to the local knowledge system of the community [8]. There are four steps taken in qualitative research, namely: data collection, data reduction, data presentation, and drawing conclusions or verification [9]. Data reduction is intended as a process of selecting, focusing on simplifying, abstracting, and transforming "rough" data from records in the field. In digging up information related to Nanaku, interviews and observations were made to fishermen around the coast of Taniwel sub-district [10]. This study also uses relevant literature studies. This literature study is needed to explain the same phenomena or have similarities with the object of study but has different locations or time periods [11]. The interviewed informants were determined by purposive sampling, that is, the type has taken based on the researcher's consideration or judgment with the assumption that the selected informants were representative of the population [12]. The results of the data collection were criticized, interpreted, and reconstructed into an article entitled Nanaku: Local Wisdom of the Coastal Fishermen Community in Taniwel Seram. 


\section{Discussion}

\subsection{Nanaku: Local Knowledge of Fishermen}

Maluku Province has an area of $712.5 \mathrm{~km} 2$, and most of its population lives in coastal areas, with its water area reaching $92.3 \% \mathrm{~km} 2$ [13]. This wide water area affects the relationship between humans and their natural environment. Most of the islands are inhabited by various ethnic groups, various marine cultures, and other local potentials, including the inhabitants of the Taniwel coast. Administratively, Taniwel is a sub-district in the West Seram District, Maluku province.

For fishing activities, the fishermen on Taniwel coast, which include Lisabata, Taniwel Hulung, and Kasieh villages, still use natural markers. These natural markers were obtained from generation to generation and served as guidelines before they went to sea. This natural condition of the sea greatly affects the knowledge and mindset of the people. They take some advantage of and use local knowledge as a result of their interaction with the natural environment. For most of the communities around Taniwel coast, being fishermen is their main livelihood. They depend on their daily life as fishermen guided by the customs, norms, values, and natural markers that they mastered. Natural markers mastered by fishermen grow, develop, transform, and are maintained through non-formal education from generation to generation. Natural signs that are owned can be in the form of animals, plants, sky objects, weather, and others. Some of them will be explained as follows:

1. Nanaku moon

The knowledge when the moon is full, or the moon is bright, is a sign that fishermen will have difficulty getting fish. Conversely, if the night is dark and there is no moonlight, there will be lots of fish and swarming the lights brought by the fishermen to the sea. This implies that fishermen will be able to obtain various types of fish in large quantities.

2. Nanaku karti star.

Knowledge of karti star characteristics is that it is marked with many stars, gathering in one point, and looks like it has a long tail. The peak of the Karti star usually appears in the sky at the end of July. When karti stars appear in the sky, it is a sign that the anchovy season is coming. The appearance of anchovies is accompanied by the appearance of other fish species such as giant trevally, skipjack, yellowfin tuna, bullet tuna and mackerel tuna because anchovies are prey (food) for these fish [14]. Those fish are classified as pelagics type that lives at a depth of about 10 to 15 meters above sea level and usually hunts anchovies and plankton. The knowledge of Nanaku karti star by fishermen on the Taniwel coast is the same as Batak people knowledge when determining the start of a new year. Batak time calculation experts usually observe two constellations that are roughly compatible with those well-known in the West as Orion and Scorpio. The new year determinant is the time of year when Orion starts to set in the western sky after dark, while Scorpio simultaneously rises in the eastern sky. Both stars are considered to have tails [15].

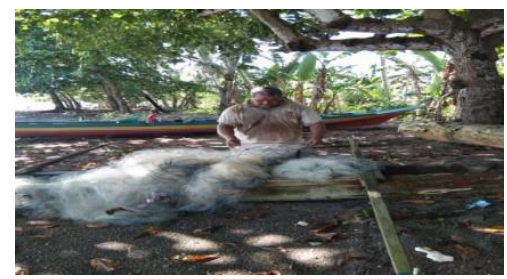

Fig. 1. A Fisherman in Hulung Village while preparing equipment to go to the sea. (Source: Author's Documentation, 2020) 


\section{Beluku star.}

Knowledge of the beluku star characteristics in the presence of stars that line up to form a line similar to z letter. Beluku star usually appears in August. If beluku star appears, then the fishermen will believe, and it will be a sign of the big fish appearance, especially whales, sharks, and many dolphins. Whales and tuna in large sizes will surround the fishing nets.

4. Nanaku scaly clouds.

This knowledge is characterized by a day when the sky has thick white clouds, and it resembles fish scales at night. This condition is a sign that various kinds of fish are looking for food, so that is the time when fishermen will get a lot of catch [16]. When the thick clouds that resemble fish scales are in the sky, the temperature is getting warmer, and the seawater is also getting warmer so that many planktons appear. This makes the fish hunt for plankton as their food.

5. Nanaku high and low tide.

The fishermen really understand the phenomenon of high and low tide. At low tide, they take advantage of time going down to the sea to catch fish because many fish are hunting for plankton. When the tide is high, sometimes fishermen have difficulty catching fish because the fish that hunt for plankton is small [17].

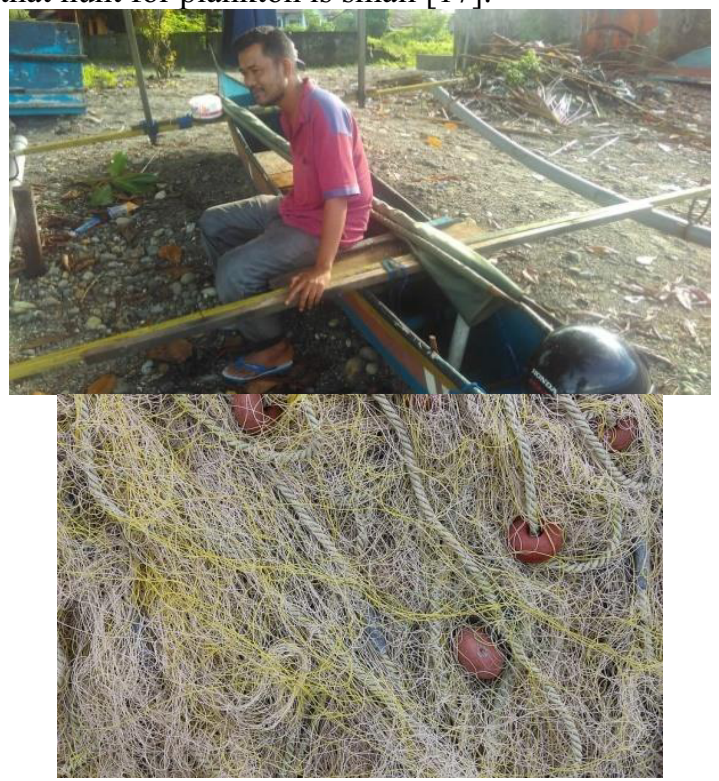

Fig. 2. Fisherman in Taniwel village ready to go to sea.

(Source: Author's document, 2020)

6. Nanaku windstorm (tornado).

When the cloud is black and looks like a banana heart and extends vertically, it is a sign that a tornado is coming. In this condition, the fishermen immediately spur the boat to avoid being hit by tornadoes that could endanger them.

7. Nanaku ocean currents

If the ocean currents are too clear and the water is too cold, this is a sign that there are no fish in that area. Seawater is said to be clear if up to a depth of 6 to 7 meters, the objects or bait used by fishermen are still seen. Likewise, if the seawater feels hot for our hands, it is a sign that fish in that area are hard to find.

8. Nanaku when river water overflows or floods and looks very muddy 
If this condition occurs, it is a sign that there are no fish in that area. Maybe there is a small amount of fish, but because the river flooded, a lot of plankton was involved, and it became fish food. At this period of time, when fishermen go to sea, they will get difficulties in catching fish.

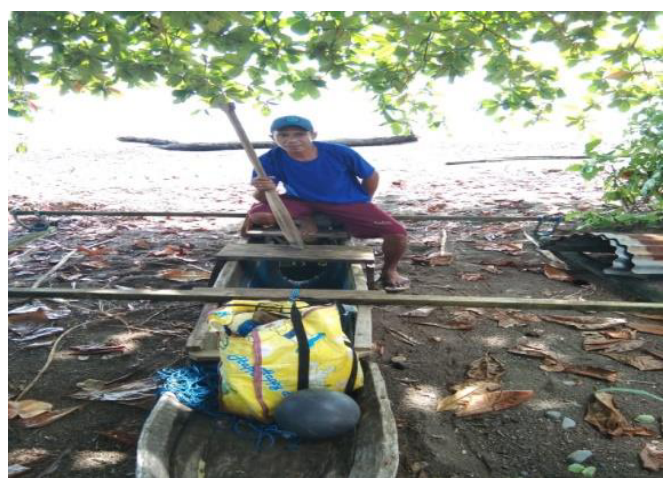

Fig. 3. A Fisherman in Hulung Village who is getting ready to go to sea

(Source: author's document, 2020)

9. Nanaku seagull flocks flying in the ocean

This condition is a sign that there are lots of tuna and kinds of stingrays in that place. This sign is the same when there are many long-tailed sibia (Heterophasia picaoides) flying over the sea, which indicates that the season is changed, both from the rainy season to the dry season and vice versa. This condition also indicates that there is a lot of fish in the sea, so it is very good for fishermen to go to the sea [18].

10. Nanaku Owl (Boel)

This sign is usually when an owl is screaming at dawn or at night. When they hear the owl scream, fishermen on Taniwel coast and especially in Kasieh village will immediately go to sea because it is confirmed that there are lots of fish [19].

11. Nanaku Lunar Eclipse

With this sign, fishermen in Kasieh village during the makarao moon (lunar eclipse) usually get water in a large container like a bucket. After the makarao moon is completed, all fishing equipment such as nets and other tools are watered using the water from the container [20]. From the habits they usually do, it turns out that they get big amounts of fish when they go to sea. This habit is carried out every time when there is a makarao moon (lunar eclipse), and the next day when they go out to sea, the catch is very satisfying.

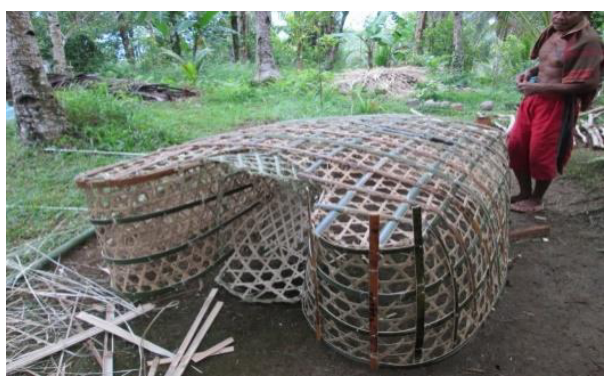

Fig. 4. A Fisherman in Kasieh village with fishing tool (bubu) made from bamboo slices.

(Source: author's document, 2020) 


\section{Nanaku Lightning in Northeast at night}

This is a sign that if there is repeated lightning in the northeastern part of the north, the turtles are coming to land to lay their eggs on the beach sand. It is the time that people living around the coast began rushing to go get turtle eggs after the mother returned to the sea [21].

\subsection{Value Transformation}

There are at least two conditions that can be seen for transformation or change; they are pre-change and post-change conditions. In the local knowledge context of the Coastal Taniwel community, transformation is an effort to preserve local culture so that it can survive and enjoy by the next generation. Transformation is a shift or movement to another or new direction without changing the structure contained in both structure and culture [22]. This transformation also involves the networks or social and ecological relationships.

Essentially, culture has values that are inherited, interpreted, and implemented in line with the process of social change [23]. Along with the value transformation process given from the preceding generation to the younger generation, of course, the knowledge gained will be put into practice. The transformation of fishermen's local knowledge in the form of nanaku on Taniwel coast is also carried out. The natural condition of the sea, which is rich in marine biota, greatly affects fishermen in utilizing it by using the knowledge. This knowledge has grown hereditary as a result of interactions between fishermen and nature; in their interactions; people gain experience and knowledge about what humans expect from their environment. This knowledge can be obtained naturally and as a result of the actions and challenges experienced by the fishermen [24]. Therefore, the Taniwel coastal fishermen's understanding of nanaku as a natural phenomenon that accumulated in mind is passed down orally and usually cannot be explained through scientific terms. This local knowledge system deals with very broad aspects of people's life, including the universe (cosmology), flora, fauna, objects, activities, as well as events that have been occurred. The local knowledge system is also related to the natural, social, and cultural environment in which these community groups live and carry out their main activities in order to survive. That is the transformation of nanaku local knowledge carried out hereditary by Taniwel coast community.

\section{Conclusion}

Nanaku local knowledge is a form of local wisdom regarding traditional knowledge owned by Taniwel coastal fishermen. This knowledge is a natural marker before the fishermen carry out fishing activities. Through nanaku, fishermen have the potential to get an increase in their catch. The coastal fishing community of Taniwel has 12 local knowledge of nanaku (natural markers). This nanaku is trusted by fishermen because it can be a guide that is trusted by the community in fishing activities. Through nanaku, fish catches will be abundant. Until now, local knowledge is still owned and transformed from generation to generation based on direct experience. The absorption pattern in a contextual form is a characteristic of non-formal education that grows in a cultural context. During its development, nanaku as local knowledge is also transformed among fishermen's families so that it is easily understood by children so that they become supporters of the cultural results. 


\section{References}

1. S. Irawati, et, al., Study on the Local Wisdom Consolidation in increasing resource productivity, (2002)

2. Kusnadi, Budaya Masyarakat Nelayan, (2001)

3. S. Touwe, Local Wisdom Values of Maritime Commonity in Preserving Marine Resources in National Indonesia, (2020)

4. E. B. Taylor, Primitive Culture Researches into the Developmen of Mythologi, Philosopphy, Religion, Art, en Cumtom, (1887); P. Suparlan, Ethnic groups and Interethnic Relations, (2005); Koentjaraningrat, Culture, Mentality and Development, (1993)

5. S. Irawati, et, al., Study on the Local Wisdom Consolidation in increasing resource productivity, (2002)

6. J. Tuhumury, Nanaku a Theological Perspective Concerning a Belief in Manuhuso Birds in Latuhalat Land and Its Implications, Journal KENOSIS, 5(2), (2019)

7. Alfian, Socio-Cultural Transformation in National Development, (1986); S. Kamanto, Process of Cultural Inheritance in Society, (1999)

8. S. Endraswara, Literary Criticism Methodology, (2013)

9. Miles, Matthew, Huberman, Michael, Qualitative Data Analysis, (1992)

10. S. Basuki, Research Methods, (2006)

11. H. Sjamsudin, Historical Methodology, (2007)

12. M. Lexy, Qualitative Research Methodology, (2000)

13. Marine and Fisheries Department, Maluku Province, (2008)

14. Interview with Mr. Tonci Kapitan in Hulung village on 13 December 2020

15. J. Angerlir, Journal Indigenous Knowledge about Time-Keeping: Astronomical Aspects of The Batak Calendar, 1(1), (2021)

16. Interview with Mr. J. Pattilou on December 16, 2020

17. Interview with Mr. Pelipus Niwele in Taniwel on 17 December 2020

18. Interview with Yus in Hulung village, December 18, 2020

19. Interview with Usman An in Kasieh village on December 20, 2020

20. Interview with Usman An in Kasieh village on December 20, 2020

21. Interview with Yus Huwae in Hulung village on December 20, 2020

22. Kuntowijoyo, Culture and Society (plenary edition), (2006); S. Pujileksono, Anthropology (revised edition), (2009)

23. H. Nurdianah, Transformation of the Local Wisdom Values as an Effort to Develop Character in Welcoming Indonesia Golden Generation, National Seminar Proceedings on Primary Education, 1(1), (2016)

24. Maria et al., Belief System in Naga Village Community in Managing the Environment, (1995) 